\title{
Variation in radular teeth and acuspid side of the radula in Lacuna pallidula, L. parva and L. vincta (Gastropoda: Littorinidae) from the Isle of Wight, United Kingdom
}

Received: 2 December 1999 / Received in revised form: 25 October 2000 / Accepted: 1 December 2000 / Published online: 19 January 2001 (C) Springer-Verlag and AWI 2001

\begin{abstract}
The variation in the radula of three species of Lacuna has been investigated and the back of the rachidian tooth is proposed as providing a new character set of potentially high taxonomic value. The term basal plate is introduced for the back of the rachidian tooth. Cusp and tooth morphology are closely related to diet and wear, and are subject to considerable homoplasy, whereas the structure of the basal plate of the rachidian tooth provides a more neutral character set. The difference in this character set between the lacunids has been quantified using seven measurements and the exploratory multivariate statistical procedure principal component analysis. The basal plate of the rachidian tooth showed interspecific differences. The taxonomic value of this new character set should be evaluated in further studies of other prosobranchs.
\end{abstract}

Keywords Radula · Variation · Lacuna $\cdot$ Littorinidae

\section{Introduction}

The radula of littorinids is of the taenioglossate type with the rachidian tooth in the centre surrounded by a pair of lateral teeth, a pair of inner marginal teeth and a pair of outer marginal teeth. In taxonomic studies the radula of littorinids must be used with caution due to considerable intraspecific variation in morphology (Borkowski 1975; Reid 1988; Padilla 1998). Recently, Padilla (1998) has shown the presence of ecophenotypic plasticity, i.e. the morphology of newly formed teeth are influenced by the substrate on which the snails feed.

Several multivariate statistical studies concerning shell morphology in littorinids have been conducted (Janson and Sundberg 1983; Johannesson and Johannesson 1990,

Communicated by R.M. Kristensen

A. Jørgensen (

Danish Bilharziasis Laboratory, Jægersborg Allé 1D,

2920 Charlottenlund, Denmark

e-mail: aj@bilharziasis.dk
1996; Sundberg 1988). The radula can be used in similar morphometric analyses. On the cusped "front" of the radula there are not many obvious structural elements that can be measured due to the partial covering by the lateral teeth. The basal plate of the rachidian tooth, on the other hand, is a structure which offers clear possibilities for measurements.

The purpose of this study is to investigate and compare the morphological variation of the radula in three species of Lacuna Turton, 1827: L. pallidula (da Costa, 1778), L. parva (da Costa, 1778) and L. vincta (Montagu, 1803), on the basis of sympatric specimens from the Isle of Wight, UK. The present study furthermore introduces the basal plate of the rachidian tooth as an adequate template for measurements which can be used in multivariate analysis.

\section{Materials and methods}

During a spring tide on 14-16 August 1997 approximately 50 specimens of each of the species Lacuna pallidula, L. parva and L. vincta were collected from Horse Ledge and Yellow Ledge $\left(50^{\circ} 37^{\prime} \mathrm{N}, 1^{\circ} 10.5^{\prime} \mathrm{E}\right)$, Shanklin, Isle of Wight, UK. All three species were collected from the red algae Chondrus crispus Stackhouse and Mastocarpus stellatus (Stackhouse). L. pallidula and L. vincta were also found on the brown algae Laminaria sp. The three species represent the commonly found Lacuna species. The fourth European species, L. crassior (Montagu, 1803), which is not part of this investigation, is rare and inhabits the soft bottom at a lower depth. This species is considered a synonym of $L$. vincta by Hubendick and Warén (1976).

The species were easily distinguishable. L. pallidula is orangegreen in colour, has a characteristically shaped aperture and nearly no spire. L. parva is predominantly unbanded white, but redbrown colour morphs are also present, and it has a slightly more pronounced spire than L. pallidula. L. vincta is banded and has a relatively well-developed spire [Fig. 1; see also Fretter and Graham (1980)].

The specimens were fixed in $4 \%$ buffered formaldehyde. For radula examination the radula was carefully removed, cleaned with $5 \%$ sodium hypochlorite to dissolve any remaining tissue and rinsed in demineralised water. The radulae were mounted individually on aluminium stubs and coated with gold. The radular teeth and basal plates of the rachidian teeth were examined with a JEOL JSM-840 scanning electron microscope (SEM). Measurements 

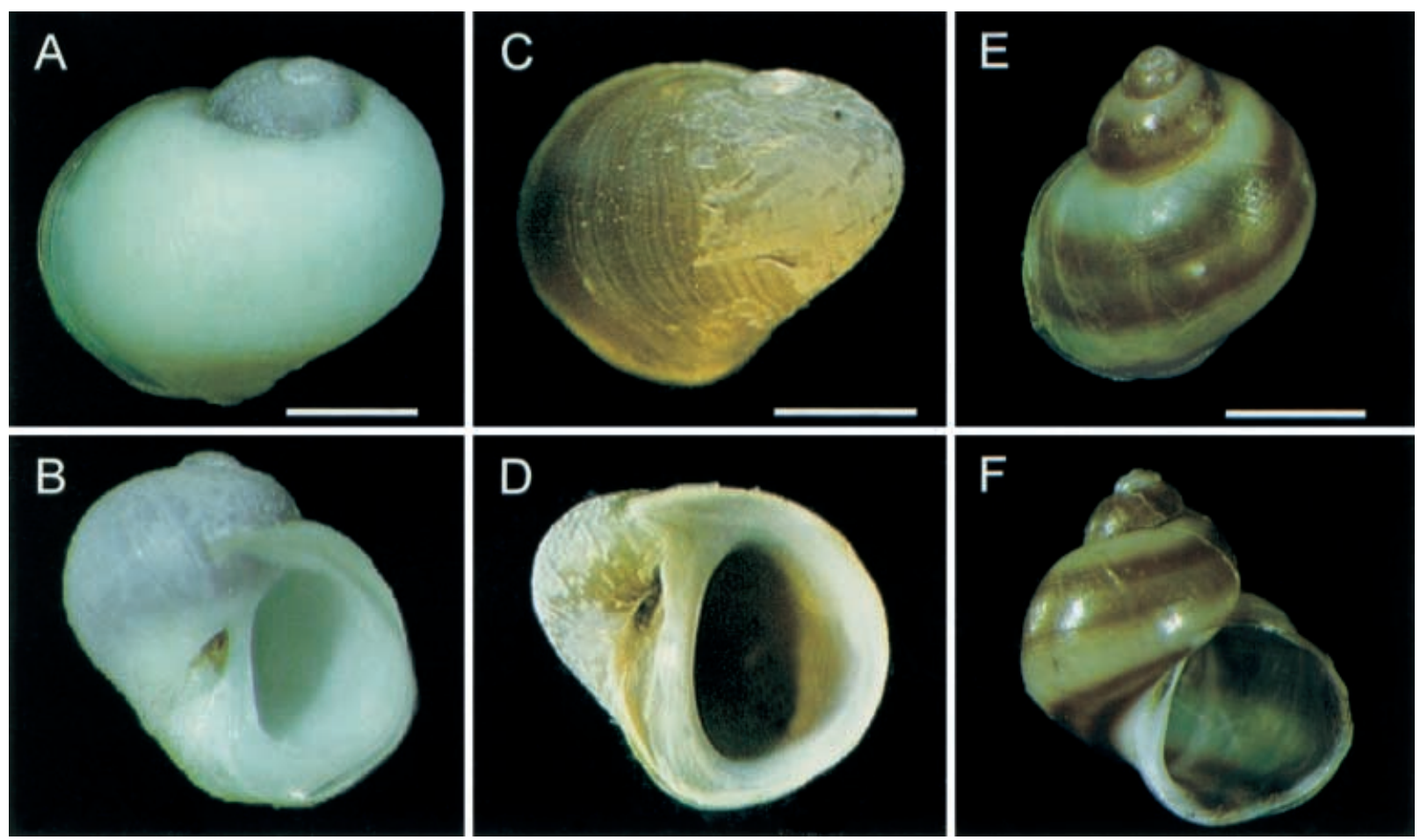

Fig. 1A-F Apertural and abapertural view of the three investigated littorinids from the Isle of Wight, UK. Lacuna parva (A and B), L. pallidula $(\mathbf{C}$ and $\mathbf{D})$ and L. vincta $(\mathbf{E}$ and $\mathbf{F})$. Note the large aperture in L. pallidula and the spire in L. vincta. Scale bars $=1 \mathrm{~mm}$

were made on photomicrographs taken at $1,000 \times$ and $1,500 \times$ magnification.

The seven measured characters of the basal plate of the rachidian tooth are described as follows: $A$ is the length measured in the centre of the tooth; $B$ is the largest width of the anterior part; $C$ is the largest width; $D$ is the largest width of the posterior part; $E$ is the width exactly between $B$ and $C$. These measurements were introduced to separate L. pallidula and L. vincta from each other. The back of the rachidian tooth of L. pallidula appears slightly more curved between $B$ and $C$ than in L. vincta, and thus has a smaller width; $F$ and $G$ are the diagonals from the points of measurement in $B$ to $D$. As the lateral teeth almost always cover part of the rachidian tooth, these measurements could not easily have been obtained from the cusped side of the radula.

Fifteen basal plates of the rachidian teeth were measured from each specimen and the mean of each of the variables was used in the statistical analysis.

Principal component analysis (PCA) was used to evaluate the quantitative data (Reyment et al. 1984). The primary aim of the PCA analysis was to quantify and illustrate the difference between the three species. The statistical analyses were conducted with SAS version 6.12.

\section{Results}

Cuspid side of the radula

I suggest the term "cuspid end" for the part of the teeth possessing cusps and opposite the "base" or acuspid end. In all three species, expanded lateral wings give the rachidian tooth a hexagonal outline which can be seen even more clearly from the back of the radula (Fig. 2).
Table 1 Intra-specific variation in the number of cusps on the different radular teeth. Asterisks indicate in which teeth intra-individual variation occurs; numbers in parentheses indicate rare conditions. $N$ Number of investigated specimens in each species

\begin{tabular}{lccc}
\hline & Lacuna pallidula & L. parva & L. vincta \\
\hline Rachidian tooth & 5 & 5 & 5 \\
Lateral teeth & 5 & 4 & $4-(5)$ \\
Inner marginal teeth & $4-5$ & $3-4$ & $4-5$ \\
Outer marginal teeth & $3-5^{*}$ & $2-(3)$ & $4-7^{*}$ \\
$N$ & 20 & 30 & 30 \\
\hline
\end{tabular}

The acuspid end ("base") of the rachidian tooth is considerably more narrow than the wings. Part of the wings is shaded by the raised shaft running from the base to the cusps (Figs. 2 and 3). In L. pallidula and L. vincta the rachidian tooth is much more longitudinally compressed than in L. parva. The lateral teeth in all three species have a well-developed littorinid notch (most clearly seen from the acuspid side), a groove for the inner marginal tooth, and the typical littorinid trapezoid base. On Fig. 2A the outer part of the littorinid notch appears thin in L. pallidula. This is due to intraspecific variation in L. pallidula; in most of the examined radulae the outer part of the littorinid notch has the same proportions as in L. parva and L. vincta (Fig. 2C, E). The inner and outer marginal teeth are elongate with simple rounded bases and do not show any significant difference between the species.

The number of cusps on the different teeth is presented in Table 1. The rachidian tooth always has five cusps and the outer pair of cusps in L. pallidula is generally more strongly developed than in the other species. The lateral teeth vary in the number of cusps only in L. vincta. The 

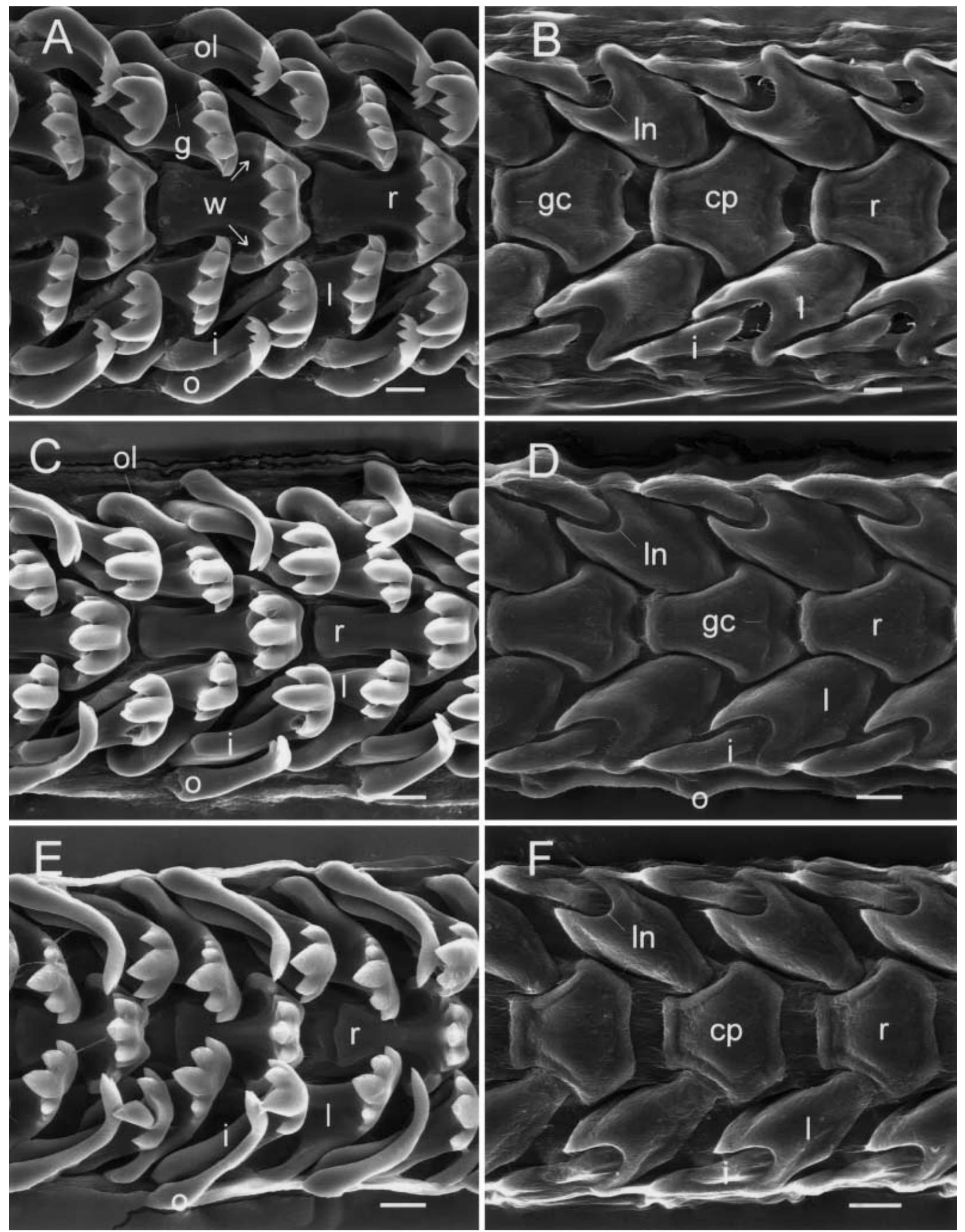

Fig. 2A-F Scanning electron micrographs of the radular teeth and back of the radula in L. pallidula $(\mathbf{A}$ and $\mathbf{B}), L$. parva $(\mathbf{C}$ and $\mathbf{D})$, and L. vincta $(\mathbf{E}$ and $\mathbf{F})$. Scale bars $=10 \mu \mathrm{m}$. $c p$ Central plateau of rachidian basal plate, $g$ groove in lateral tooth, $g c$ groove sur- rounding the cp, $i$ inner marginal tooth, $l$ lateral tooth, $\ln$ littorinid notch, $o$ outer marginal tooth, ol outer part of lateral tooth, $r$ rachidian tooth, $w$ lateral expansions (wings) 
A

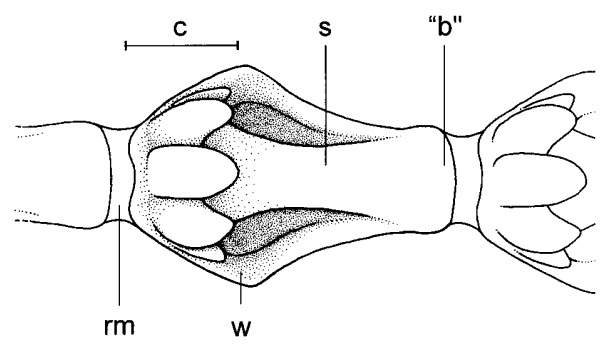

B

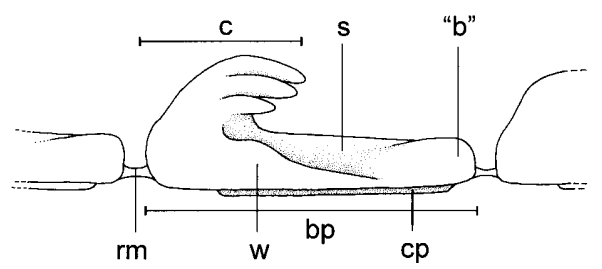

C

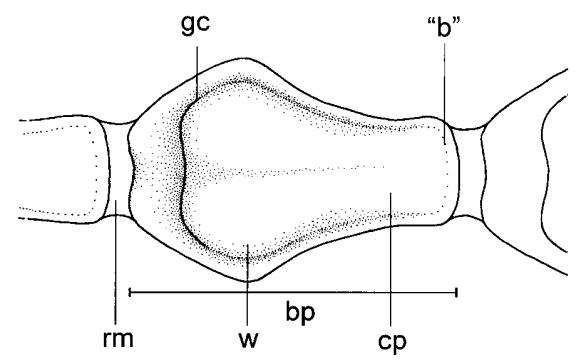

Fig. 3A-C Different views of the rachidian tooth. A frontal view, B lateral view, $\mathbf{C}$ view of the back of the basal plate. " $b$ " Traditionally termed the "base", $b p$ basal plate, $c$ cuspid part or end, $r m$ remnants of the radular membrane, $s$ shaft; for other abbreviations, see Fig. 2

number of cusps on the marginal teeth is very plastic and varies even within a single specimen. The number of cusps on the outer marginal teeth of L. parva, which almost always is 2, is less variable than in the other species (Table 1).

The back of the radula

The use of the back of the radula gives the opportunity to investigate structures of the teeth not previously considered in littorinid taxonomy. Structures of the examined teeth and structures which are covered by other teeth when viewed from the front are clearly visible.

What has traditionally been termed the "base" of the teeth is an inappropriate term for the rachidian tooth, which lies embedded in the radular membrane with the cusps facing upwards (Fig. 3A). The embedded side is the actual base of the rachidian tooth, so in the present account the term "basal plate" is adopted from patellogastropod terminology to refer to this structure (Fig. 3B, C). The term "base" is appropriate for the end

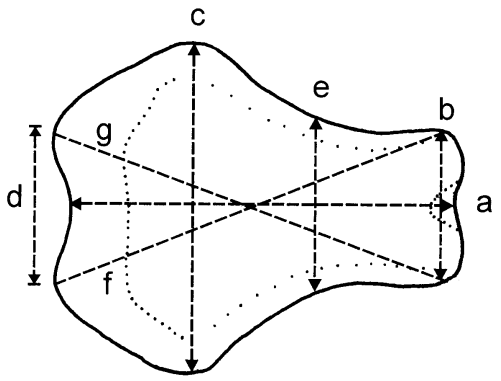

Fig. 4 Schematic drawing of the basal plate of the rachidian tooth of L. parva. The dotted line indicates the groove between the tooth outline and the cp. The measurements are explained in the text

opposite the cusps in the marginal teeth, in which the base actually is embedded in the radular membrane. The term basal plate can also be used for the back of the lateral tooth.

The basal plate of the rachidian tooth provides a new character set in littorinid taxonomy. Therefore it is necessary to describe its morphology and to introduce some new terminology regarding its orientation (Fig. 3). The back of the rachidian tooth is the side opposite to the cusped front and constitutes the basis of the tooth, hence the term basal plate is introduced. The basal plate is the structure of the tooth closest to the radular membrane. It is actually embedded in the radular membrane and careful removal of the membrane by sodium hypochlorite is necessary for the basal plate to be laid bare. The basal plate differs from the cusped front in the outline of the tooth; it is not merely a flat uniform structure, but has characteristics of its own. The basal plate appears to have less of a constriction or "waist" close to the "base" when compared with the front (Fig. 2). This is the result of an undisturbed view of the outline of the wings, as it is presented from the back, until they merge with the base of the tooth. When viewed from the front the wings are partially covered by the lateral teeth, and the shadow effect of the different levels of the shaft (raised) and the wings (background) easily results in misinterpretation of the rachidian outline (Fig. 2A, C, E). On the basal plate of the tooth the "base", wings, and cusped part of the tooth can easily be recognised as constituting the outline. Furthermore, a raised central plateau surrounded by a groove can be recognised (Figs. 2B, D, F and 4C). The central plateau is slightly divided into two raised parts along the midline, as indicated by the shadowing in Fig. 3C. Especially in L. vincta, there is a prominent edge between the outline and the groove.

The basal plate of the rachidian tooth in L. pallidula and $L$. vincta clearly shows that it is more longitudinally compressed than in L. parva. In contrast, L. pallidula and $L$. parva have a similar curvature from the most extended point of the wings to the base of the tooth, which in L. vincta is almost straight. 
Table 2 Result of the principal component analysis of logtransformed variables. Note the good summary of the variation in the data set given by the first two principal components.

$A$ Length measured in the centre of the tooth, $B$ largest width of the anterior part, $C$ largest width, $D$ largest width of the posterior part, $E$ is the width exactly between $B$ and $C, F$ and $G$ are the diagonals from the points of measurement in $B$ to $D$

\begin{tabular}{|c|c|c|c|c|c|c|c|c|}
\hline Component & & 1 & 2 & 3 & 4 & 5 & 6 & 7 \\
\hline Eigenvalue & & 4.533 & 2.215 & 0.103 & 0.100 & 0.042 & 0.007 & 0.001 \\
\hline Cumulative $\%$ & & 64.76 & 96.40 & 97.87 & 99.29 & 99.89 & 99.99 & 100.0 \\
\hline \multicolumn{9}{|l|}{ Eigenvectors } \\
\hline \multirow[t]{7}{*}{ Character } & A & 0.356 & -0.434 & -0.004 & 0.064 & 0.303 & 0.764 & 0.070 \\
\hline & B & 0.408 & 0.275 & -0.684 & 0.532 & -0.012 & -0.076 & -0.021 \\
\hline & $\mathrm{C}$ & 0.458 & 0.077 & 0.104 & 0.251 & -0.824 & 0.178 & 0.011 \\
\hline & $\mathrm{D}$ & 0.334 & 0.443 & -0.172 & -0.700 & 0.416 & -0.011 & -0.002 \\
\hline & $\mathrm{E}$ & 0.249 & 0.545 & 0.665 & 0.401 & 0.172 & 0.094 & 0.013 \\
\hline & $\mathrm{F}$ & 0.400 & -0.349 & 0.166 & 0.008 & 0.120 & -0.364 & -0.738 \\
\hline & G & 0.404 & -0.340 & 0.146 & 0.013 & 0.110 & -0.487 & 0.671 \\
\hline
\end{tabular}

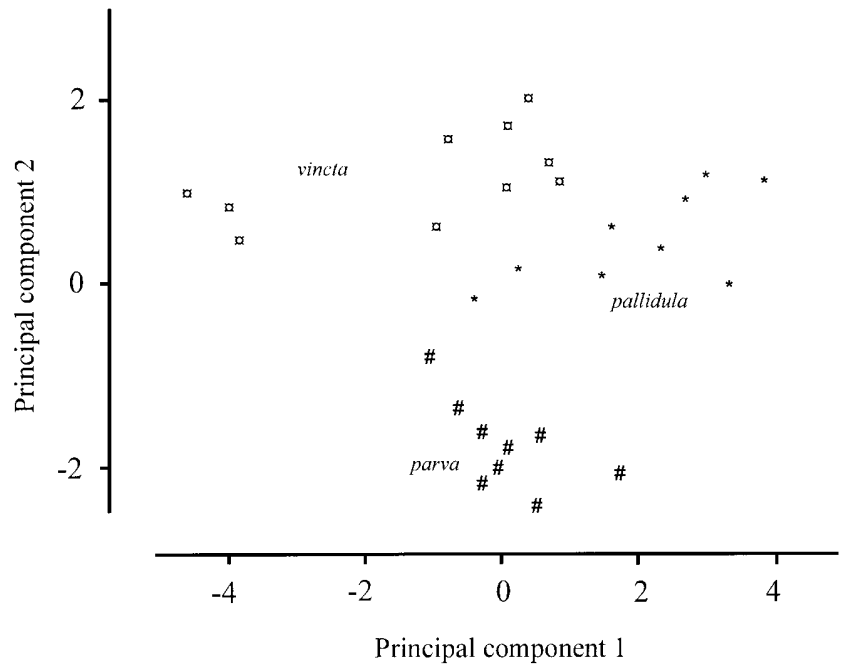

Fig. 5 Plot of the first and second principal components illustrating the dispersion of species, L. pallidula (*), L. parva (\#), and L. vincta ( ). Note that the scales are not the same on the axes

\section{Multivariate analysis}

In the plot which illustrates the species distribution in relation to the first two principal components, $L$. parva is clearly isolated, while L. pallidula and L. vincta are less distinctly separated from each other (Fig. 5).

The characters measured on the basal plate of the rachidian tooth are highly correlated with each other, and the first two principal components explain $>95 \%$ of the variation between the characters (Table 2). Character $c$ on Fig. 4 is the single most important variable to contribute to the first principal component, and character $e$ contributes most to the second principal component (Table 2).

\section{Discussion}

The observed plasticity in the number of cusps on the marginal teeth reduces their use in taxonomic and systematic investigations. The possible homoplasy in these characters within a genus or between genera is very large. Reid (1989) stated that the number of cusps in the outer marginal teeth of Lacuna varied between one and four. The present study reports as many as five and seven cusps in the outer marginal teeth of L. pallidula and L. vincta, respectively. Tooth morphology is related to diet and cusp shape displays considerable ecophenotypic plasticity (Padilla 1998) and is therefore potentially subject to homoplasy; this is not necessarily the case with the basal plate of the rachidian tooth. So even if tooth morphology is similar due to convergence it might be possible to discriminate between species using the basal plate of the rachidian tooth. Marshall (1987) includes the back of the radular teeth in establishing homologies in them among different families of limpets.

L. pallidula and L. vincta occur in the littoral zone, with L. vincta occurring in the sublittoral as well (Grahame 1985). They are not as specific in their choice of dietary algae as $L$. parva, which is sublittoral in its distribution (Ockelmann and Nielsen 1981; A. J. personal observation). The greater variability of the radulae in $L$. pallidula and $L$. vincta could be related to their occurrence on a wider range of substrates.

$L$. pallidula and $L$. parva are classified in the subgenus Lacuna Turton, 1827 and L. vincta in the subgenus Epheria Leach, in Gray, 1847 (Reid 1989). Even though L. pallidula and L. parva are classified in the same subgenus the basal plate of the rachidian tooth is actually more similar in L. pallidula and L. vincta.

The PCA separated the three species of Lacuna, and most clearly $L$. parva. As stated earlier, L. parva is known to feed on a limited number of red algae (Ockelmann and Nielsen 1981; A. J. personal observation). This specialisation could be the reason for the less scattered distribution of this species in the principal components plot. The analysis summarises the variation in the data set well; this demonstrates the usefulness of the basal plate in multivariate analyses.

The recent examples of ecophenotypic plasticity in littorinid radulae (Padilla 1998; Reid and Mak 1999) emphasise that one should be very careful when using radula morphology as a taxonomic and systematic tool. The present study has used specimens collected from the same species of algae, but the greater radular variation displayed by $L$. pallidula and L. vincta in the principal component plot could be an indication of greater ecophenotypic plasticity than in L. parva. 
The morphology of the basal plate of the rachidian tooth in other prosobranch genera looks very different from that in Lacuna (A. J. personal observation). For example, in Littorina littorea (Linnaeus, 1758) it is more hourglass shaped than in Lacuna. The basal plate of the rachidian tooth is more than just the opposite side of the tooth, as it has structures of its own (e.g. a groove along the outline and a central plateau). Further investigations should examine the usefulness of this character set in taxonomic and phylogenetic studies concerning other prosobranch taxa.

Acknowledgements Dr Ian Killeen drew my attention to the sampling localities and his helpfulness is greatly appreciated. Stine Elle is thanked for preparing the drawings of the rachidian tooth. The help and patience of my wife, Nadja Møbjerg, during all stages of the field work was indispensable. Dr Claus Nielsen is thanked for his many useful comments on various versions of the manuscript, and Dr Mary E. Petersen for linguistic corrections. This research project was supported by grants from The Danish Natural History Society and Winges Museums Legat.

\section{References}

Borkowski TV (1975) Variability among Caribbean Littorinidae. Veliger 17:369-378

Fretter V, Graham A (1980) The prosobranch molluscs of Britain and Denmark. Part 5. Marine Littorinacea. J Moll Stud [Suppl] $7: 243-284$

Grahame J (1985) The population biology of two species of Lacu$n a$ (chink-shells) at Robin Hood's Bay. In: Moore PG, Seed R, (eds) The ecology of rocky coasts. Hodder and Stoughton, London

Hubendick B, Warén A (1976) Framgälade Snäckor fran svenska Västkusten. Göteborgs Naturhistoriska Museum, Göteborg

Janson K, Sundberg P (1983) Multivariate morphometric analysis of two varieties of Littorina saxatilis from the Swedish west coast. Mar Biol 74:49-53

Johannesson B, Johannesson K (1990) Littorina neglecta Bean, a morphological form within the variable species Littorina saxatilis (Olivi)? Hydrobiologia 193:71-87

Johannesson B, Johannesson K (1996) Population differences in behaviour and morphology in Littorina saxatilis: phenotypic plasticity or genetic differentiation? J Zool 240:475-493

Marshall BA (1987) Osteopeltidae (Mollusca: Gastropoda): a new family of limpets associated with whale bone in the deep-sea. J Moll Stud 53:121-127

Ockelmann KW, Nielsen C (1981) On the biology of the prosobranch Lacuna parva in the Øresund. Ophelia 20:1-16

Padilla DK (1998) Inducible phenotypic plasticity of the radula in Lacuna (Gastropoda: Littorinidae). Veliger 41:201-204

Reid DG (1988) The genera Bembicium and Risellopsis (Gastropoda: Littorinidae) in Australia and New Zealand. Rec Aust Mus 40:91-150

Reid DG (1989) The comparative morphology, phylogeny and evolution of the gastropod family Littorinidae. Phil Trans R Soc London 324:1-110

Reid DG, Mak Y-M (1999) Indirect evidence for ecophenotypic plasticity in radular dentition of Littoraria species (Gastropoda: Littorinidae). J Moll Stud 65:355-370

Reyment RA, Blackith RE, Campbell NA (1984) Multivariate morphometrics, 2nd edn. Academic Press, London

Sundberg P (1988) Microgeographic variation in shell characters of Littorina saxatilis Olivi - a question mainly of size? Biol J Linn Soc 35:169-184 